\title{
Identification and analysis of methylation call differences between bisulfite microarray and bisulfite sequencing data with statistical learning techniques
}

\author{
Matthias Döring ${ }^{1 *}$, Gilles Gasparoni ${ }^{2}$, Jasmin Gries ${ }^{2}$, Karl Nordström²$^{2}$, Pavlo Lutsik², Jörn Walter ${ }^{2}$, Nico Pfeifer ${ }^{1}$ \\ From Third International Society for Computational Biology (ISCB) European Student Council Symposium \\ 2014 \\ Strasbourg, France. 6 September 2014
}

\section{Background}

DNA methylation is an epigenetic modification known to play a prime role in gene silencing and is an important topic in epigenetic research. However, due to technology-dependent errors there are inconsistencies between methylation measurements from different methods [1]. Incorrect methylation calls could result in the discovery of spurious associations between methylation patterns and specific phenotypes in epigenomewide association studies (EWAS). We worked towards assigning a measure of confidence to individual $\mathrm{CpGs}$ to down-weigh or exclude positions with inconsistent measurements in such studies. We used methylation measurements from the Infinium HumanMethylation450 microarray $(\beta 450 \mathrm{~K})$ and whole genome bisulfite sequencing ( $\beta$ WGBS) to evaluate whether locus-specific measurement differences, $\Delta \beta=\beta 450 \mathrm{~K}-\beta \mathrm{WGBS}$, are predictable using statistical learning techniques.

\section{Methods}

Methylation for Illumina WGBS data from HepaRGd7R2 was called with Bis-SNP [2], while methylation for Infinium $450 \mathrm{~K}$ data from the same cell line was determined using RnBeads [3] and normalized with BMIQ [4]. For a uniform feature representation, we considered windows of reads overlapping with CpGs on the microarray (Figure 1). As predictors we examined sets of read sequences, their consensus sequences (with and without base

'Department of Computational Biology and Applied Algorithmics, Max Planck Institute for Informatics, Campus E1 4, 66123 Saarbrücken, Germany Full list of author information is available at the end of the article frequencies), and non-sequence features such as base quality and depth of coverage. To obtain a predictive model independent of the methylation state, we masked CpG positions by introducing gaps or zeroing base frequencies.

To predict $\Delta \beta$, we built support vector regression models based on Illumina WGBS data. Read similarity was measured with numerical, string [5-7], and set kernels [8]. We introduced the notion of hybrid string kernels to afford a similarity measure for both numeric and string input simultaneously. These kernels are based on scaling the motif similarity scores of two sequences according to the similarity of their base frequency profiles.

\section{Results}

For a read-based set kernel utilizing the weighted degree kernel with shifts [6], we found that the predicted values of $\Delta \beta$ correlated significantly with the observed outcomes $(r=0.37$, p-value $<2.2 \cdot 10-16)$. Furthermore, the hybrid weighted degree kernel $(r=0.234)$ outperformed the weighted degree kernel with shifts $(r=0.22)$ by also considering the frequencies of individual bases in addition to the consensus sequences. Non-sequence features were less predictive of the outcome than the sequence, e.g., RBF kernels on base quality and depth of coverage attained only correlations of $r=0.057$ and $r=$ 0.003 with the outcome, respectively.

\section{Conclusion}

To our knowledge, this is the first approach indicating that differences between methylation measurements 


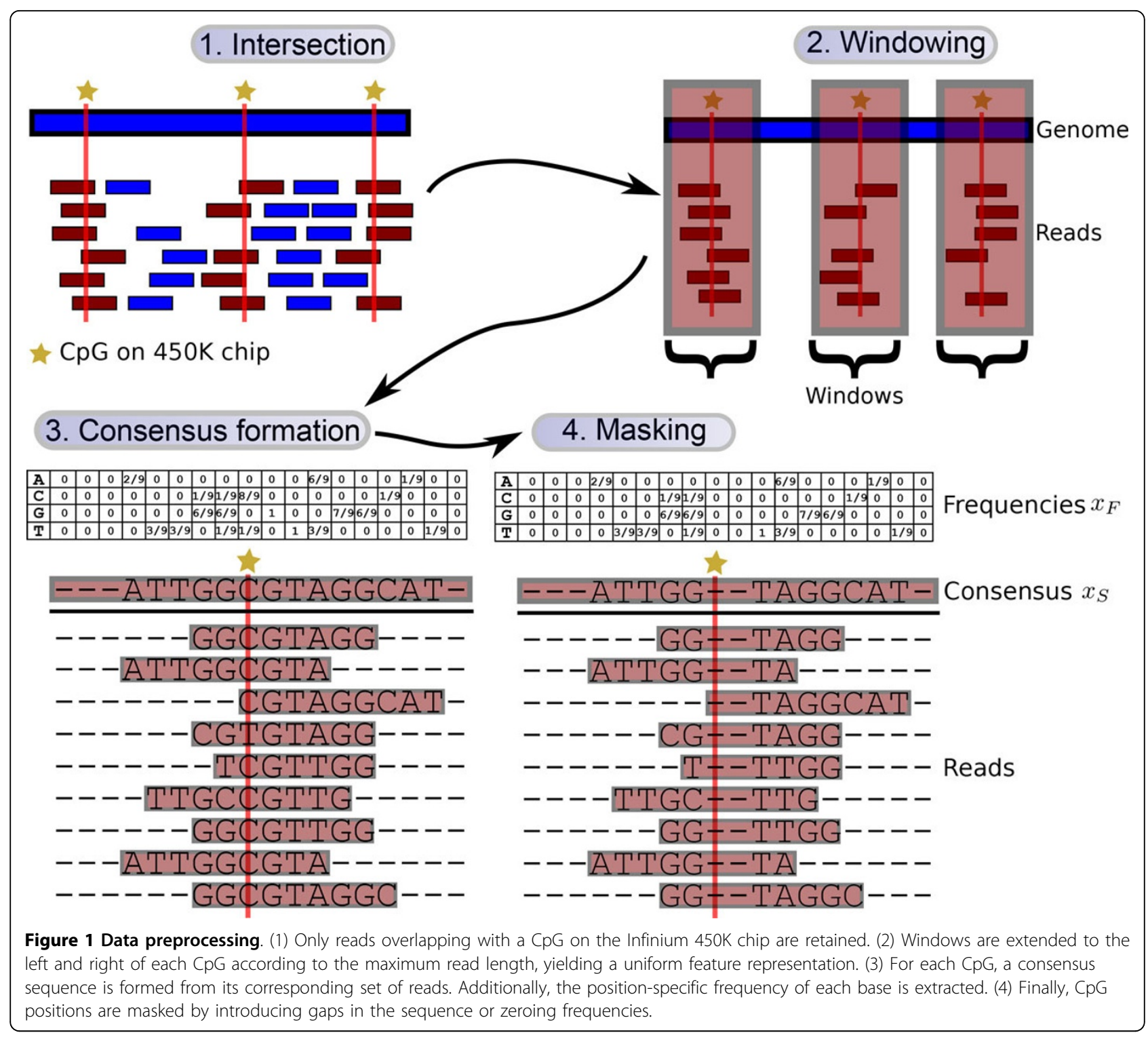

from bisulfite sequencing and the Infinium HumanMethylation450 microarray are predictable from the reads. The results suggest that features beside the sequence play only a minuscule role in the emergence of inconsistent methylation measurements. We were able to show that, in this scenario, set kernels and hybrid string kernels provide well-suited similarity measures. Further work is necessary to validate the model's generalizability for data from other cell lines and to evaluate its practical merit.

\section{Acknowledgements}

Gilles Gasparoni and Karl Nordström were funded by the BMBF project 01KU1216F (DEEP). Pavlo Lutsik was funded by the European Union's Seventh Framework Programme (FP7/2007-2013) grant agreement No. 267038 (NOTOX).

\section{Authors' details}

'Department of Computational Biology and Applied Algorithmics, Max Planck Institute for Informatics, Campus E1 4, 66123 Saarbrücken, Germany.

${ }^{2}$ Department of Genetics/Epigenetics, Saarland University, Saarbrücken, Germany.

Published: 13 February 2015

\section{References}

1. Dedeurwaerder S, Defrance M, Calonne C, Denis H, Sotiriou C, Fuks F: Evaluation of the Infinium Methylation 450K technology. Epigenomics 2011, 3(6):771-784.

2. Liu Y, Siegmund KD, Laird PW, Berman BP, et al: Bis-SNP: Combined DNA methylation and SNP calling for Bisulfite-seq data. Genome Biol 2012, 13(7):R61.

3. Assenov Y, Müller F, Lutsik P, Walter J, Lengauer T, Bock C: Comprehensive Analysis of DNA Methylation Data with RnBeads. Nat Methods.

4. Teschendorff $A E$, et al: $A$ beta-mixture quantile normalization method for correcting probe design bias in Illumina Infinium 450K DNA methylation data. Bioinformatics 2013, 29(2):189-196. 
5. Sonnenburg S, Rätsch G, Schäfer G: Learning interpretable SVMs for biological sequence classification. Research in Computational Molecular Biology Springer; 2005, 389-407.

6. Rätsch G, Sonnenburg S, Schölkopf B: RASE: recognition of alternatively spliced exons in C. elegans. Bioinformatics 2005, 21(suppl 1):i369-i377.

7. Meinicke P, Tech M, Morgenstern B, Merkl R: Oligo kernels for datamining on biological sequences: a case study on prokaryotic translation initiation sites. BMC Bioinformatics 2004, 5(1):169.

8. Gärtner T, Flach PA, Kowalczyk A, Smola AJ: Multi-Instance Kernels. Proceedings of 19th International Conference on Machine Learning San Mateo, CA: Morgan Kaufman; 2002, 179-186, Edited by Sammut C, Hoffmann A.

doi:10.1186/1471-2105-16-S3-A7

Cite this article as: Döring et al:: Identification and analysis of methylation call differences between bisulfite microarray and bisulfite sequencing data with statistical learning techniques. BMC Bioinformatics 2015 16(Suppl 3):A7.

\section{Submit your next manuscript to BioMed Central} and take full advantage of:

- Convenient online submission

- Thorough peer review

- No space constraints or color figure charges

- Immediate publication on acceptance

- Inclusion in PubMed, CAS, Scopus and Google Scholar

- Research which is freely available for redistribution

Submit your manuscript at www.biomedcentral.com/submit 